\title{
Bone Morphogenetic Protein Antagonist Noggin Promotes Skin Tumorigenesis via Stimulation of the Wnt and Shh Signaling Pathways
}

\author{
Andrey A. Sharov, ${ }^{*}$ Andrei N. Mardaryev, ${ }^{, \dagger}$ \\ Tatyana Y. Sharova, ${ }^{*}$ Marina Grachtchouk, ${ }^{\neq}$ \\ Ruzanna Atoyan, ${ }^{*}$ H. Randolph Byers, ${ }^{*}$ \\ John T. Seykora, ${ }^{\S}$ Paul Overbeek, " \\ Andrzej Dlugosz, ${ }^{\ddagger}$ and Vladimir A. Botchkarev*† \\ From the Department of Dermatology," Boston University School \\ of Medicine, Boston, Massachusetts; the Centre for Skin Sciences, ${ }^{\dagger}$ \\ School of Life Sciences, University of Bradford, United Kingdom; \\ the Department of Dermatology, ${ }^{\ddagger}$ University of Michigan, Ann \\ Arbor, Michigan; the Department of Dermatology, ${ }^{\S}$ University of \\ Pennsylvania, Philadelphia, Pennsylvania; and the Department \\ of Molecular and Cellular Biology, "aylor College of Medicine, \\ Houston, Texas
}

Bone morphogenetic proteins (BMPs) play pivotal roles in the regulation of skin development. To study the role of BMPs in skin tumorigenesis, BMP antagonist noggin was used to generate keratin 14-targeted transgenic mice. In contrast to wild-type mice, transgenic mice developed spontaneous hair follicle-derived tumors, which resemble human trichofolliculoma. Global gene expression profiles revealed that in contrast to anagen hair follicles of wild-type mice, tumors of transgenic mice showed stage-dependent increases in the expression of genes encoding the selected components of Wnt and Shh pathways. Specifically, expression of the Wnt ligands increased at the initiation stage of tumor formation, whereas expression of the Wnt antagonist and tumor suppressor Wnt inhibitory factor-1 decreased, as compared with fully developed tumors. In contrast, expression of the components of Shh pathway increased in fully developed tumors, as compared with the tumor placodes. Consistent with the expression data, pharmacological treatment of transgenic mice with Wnt and Shh antagonists resulted in the stage-dependent inhibition of tumor initiation, and progression, respectively. Furthermore, BMP signaling stimulated Wnt inhibitory factor-1 expression and promoter activity in cultured tumor cells and HaCaT keratinocytes, as well as inhibited Shh expression, as compared with the corresponding controls. Thus, tumor suppressor activity of the BMPs in skin epithelium depends on the local concentrations of noggin and is mediated at least in part via stage-dependent antagonizing of Wnt and Shh signaling pathways. (Am J Pathol 2009, 175:1303-1314; DOI: 10.2353/ajpath.2009.090163)

Skin cancer is the most common cancer in the United States, Europe, and other countries, and the incidence continues to increase. ${ }^{1}$ During the last decade, considerable progress has been achieved in identification of molecular mechanisms underlying the development of the major cutaneous cancers, such as malignant melanoma, basal cell carcinoma, and squamous cell carcinoma. ${ }^{2,3}$ In particular, it was shown that mechanisms controlling skin development and carcinogenesis appear to be very similar, and key signaling pathways (Wnt, hedgehog, notch, transforming growth factor- $\beta$, etc) that regulate skin development are also implicated in the pathobiology of cutaneous neoplasias [reviewed in ${ }^{1-5}$ ].

Bone morphogenetic protein (BMP) signaling plays pivotal roles in the control of cutaneous development and also possesses a potent antitumor activity in postnatal skin [for review see ${ }^{6,7}$ ]. BMP signaling is activated by binding of the BMP ligands to BMP receptors (BMPRs) followed by activation of the BMP-Smad and/or BMPMAP kinase pathways. ${ }^{8}$ In the extracellular space, BMP signaling is modulated by a number of BMP antagonists

Supported by grants from the National Institutes of Health (AR49778) and Biotechnology and Biological Sciences Research Coucil (BB/E023010/1) to V.A.B., and the American Skin Association and American Cancer Society (IRG) to A.A.S.

A.A.S. and A.N.M. contributed equally to this work.

Accepted for publication June 16, 2009.

Supplemental material for this article can be found on http://ajp. amjpathol.org.

Address reprint requests to Vladimir A. Botchkarev, M.D., Ph.D., Centre for Skin Sciences, School of Life Sciences, University of Bradford, Bradford BD7 1DP, UK, E-mail: v.a.botchkarev@bradford.ac.uk or Department of Dermatology, Boston University, 609 Albany Street, Boston, MA 02118. E-mail: vladbotc@bu.edu. 
including Noggin, which binds selected BMP ligands (BMP-2/4/7, growth/differentiation factor-5) with high affinity and prevents their interaction with cell surface BMP receptors. ${ }^{6}$

Many indications suggest BMP signaling as a powerful regulator of cell proliferation and differentiation in developing and postnatal skin. BMP signaling inhibits the initiation phase of hair follicle (HF) development ${ }^{9}$ and is required for proper control of keratinocyte differentiation into HF-specific cell lineages. ${ }^{10-13}$ In adult skin, BMP signaling is involved in the control of HF cycling, HF size, and in hair pigmentation. ${ }^{14-16}$

Several indications also suggest that BMP signaling contributes to skin carcinogenesis: overexpression of BMP4/6 in murine epidermis is accompanied by increased resistance to chemically induced carcinogenesis, while conditional ablation of the BMPR-IA in keratinocytes result in formation of HF-derived tumors. ${ }^{12,17,18}$ Furthermore, in chemically induced murine epidermal tumors and in human basal cell carcinoma cells, Smad1/5 are strongly down-regulated. ${ }^{19}$ Skin-specific disruption of Smad4 results in increased epidermal proliferation consequently leading to squamous cell carcinoma formation. ${ }^{20,21}$ Antitumor activity of BMPs may also be regulated by extracellular BMP inhibitors: expression of the BMP antagonist gremlin increased in basal cell carcinomas, in which gremlin promotes and BMPs inhibit cell proliferation. $^{22}$

However, mechanisms and downstream targets that mediate tumor suppressor function of the BMP signaling pathway in skin remain to be explored. In this paper, we provide evidence that K14-driven noggin overexpression in mice results in spontaneous development of trichofolliculoma-like tumors. We also demonstrate that tumor initiation and progression in K14-Noggin mice most likely occur due to abnormally activated Wnt and Shh signaling pathways, respectively. Furthermore, we show that BMP signaling may suppress tumor formation via stimulating the expression of the Wnt inhibitory factor-1 (Wif1). These data suggest that tumor-suppressive activity of BMPs in skin epithelium is modulated by local concentrations of noggin and that BMP signaling may suppress skin tumorigenesis at least in part via antagonizing the Wnt and Shh pathways.

\section{Materials and Methods}

\section{Animals, Tissue Collection, Pharmacological Experiments, and Morphometric Analyses}

All animal and human studies were performed under protocols approved by the Boston University Institutional Animal Care and Use Committee and Institutional Review Board. K14-noggin overexpressing mice were generated on FVB background by using transgenic (TG) construct containing human K14 promoter, mouse noggin cDNA (provided by R. Harland) and human growth hormone poly-A sequence, as described previously. ${ }^{23}$ Skin samples were collected from neonatal (postnatal days [P]0.5 to P21) and adult mice ( 5 to 30 weeks old, $n=5$ to 7 per time points for each mouse strain), frozen in liquid nitrogen, and embedded, as described elsewhere. ${ }^{9}$ Samples of human skin were obtained from 35- to 65-year-old individuals of both sexes from different body areas. Administration of the Wht antagonist Aptosyn (4 mg/kg, s/c daily; OSI Pharmaceuticals, Farmingdale, NY) and Shh inhibitor cyclopamine (100 $\mu \mathrm{g} / \mathrm{kg}$, s/c daily, P10 to P28; kindly provided by Dr. W. Niu, Infinity Pharmaceuticals, Inc., Cambridge, MA) or vehicle control were preformed to neonatal mice $(n=24)$, and skin was harvested and processed for histological and morphometric analyses, which were performed using bright-field microscope (Nikon), SPOT digital camera and image analysis software (Diagnostic Instruments, Sterling Heights, MI). Based on the morphology, HF-derived tumors were divided into several groups: stage 1 - small tumors (30 to $60 \mu \mathrm{m}$ in diameter) arising from the HF outer root sheath; stage 2 medium-sized tumors (60 to $120 \mu \mathrm{m}$ in diameter); stage 3 - single large tumors (over $120 \mu \mathrm{m}$ in diameter); and, stage 4 - multiple large tumors with epithelioid cyst containing keratinized substance in the center. Percentage of HFs with tumors at distinct stage of development was assessed in the control and cyclopamine-treated groups at P21 and P28, data were pooled, mean \pm SEM was calculated, and statistical analysis was performed using unpaired Student's $t$-test.

\section{Laser Capture Microdissection and Microarray Analyses}

The distinct areas from the hair matrix of anagen HFs of wild-type mice and tumor epithelium of K14-noggin mice were dissected by laser capture microdissection (Arcturus, Mountain View, CA), as described before. ${ }^{16}$ Briefly, 8- $\mu \mathrm{m}$ thick frozen sections have been extensively dehydrated to preserve RNA integrity, laser capture was performed from 50 to $70 \mathrm{HFs}$ of wild-type (WT) and TG mice, respectively. Total RNA was isolated using the PicoPure RNA Isolation Kit (Arcturus, Mountain View, CA), following by two rounds of linear RNA amplification using the RiboAmp RNA Amplification Kit (Arcturus, Mountain View, CA). The Universal Mouse Reference RNA (Stratagene, La Jolla, CA) was used after one round of linear amplification in all analyses as control. All microarray analyses were performed by Mogene Co. (St. Louis, MO) using $41 \mathrm{~K}$ Whole Mouse Genome 60-mer oligo-microarray (manufactured by Agilent Technologies).

Real-time PCR of unamplified reference RNA and reference RNA obtained after two rounds of amplification was used for validation of possible alterations in gene expression caused by amplification procedure (see below). All microarray data on gene expression were normalized to the corresponding data obtained from the reference RNA, as described previously. ${ }^{16}$ Two independent data sets were obtained from WT and TG mice, and $P$ values were calculated by the Agilent feature Extraction software (version 7.5) using distribution of the background intensity values to signal intensity and using Student's $t$-test. Functional annotation of the overrepresented and underrepresented genes was performed 
Table 1. List of PCR Primers

\begin{tabular}{|c|c|c|}
\hline Accession number & Sequence definition & Sense/anti-sense primers \\
\hline NM_009744 & B-cell leukemia/lymphoma 6 (BCL6) & $\begin{array}{l}5^{\prime} \text {-CATACCTGTAATGTGTCCTCAC-3' } \\
5^{\prime} \text {-ACAAGCATGACGCAGAATG-3' }\end{array}$ \\
\hline NM_00761 & Caspase 7 (Casp7) & $\begin{array}{l}5^{\prime}-\text { TGTAAGAGGACTTCGGTTC-3' } \\
5^{\prime}-\text { GACTCAGTTCTGGCTTGG-3' }\end{array}$ \\
\hline NM_009829 & Cyclin D2 (Ccnd2) & $\begin{array}{l}5^{\prime}-\text { TACCTTAGACAGTCCAACCTTG } \sim 3^{\prime} \\
5^{\prime}-\text { GCTGTTGACCACCACCTG-3' }\end{array}$ \\
\hline NM_007634 & Cyclin F (Ccnf) & $\begin{array}{l}\text { 5'-AGGAGAGCGAAGGCGAGAAG-3' } \\
5^{\prime} \text {-GTTCAGGTAGACCACAGTGACATC-3' }\end{array}$ \\
\hline BC052714 & Cyclin M3 (Ccnm3) & $\begin{array}{l}5^{\prime} \text {-CTGCTGGAGAATACTAACC-3' } \\
5^{\prime} \text {-GTCTATGGAACAGTCTATGG-3' }\end{array}$ \\
\hline NM_010100 & Ectodysplasin-A receptor (Edar) & $\begin{array}{l}5^{\prime} \text {-CCCACCGAGTTGCCGTTT 3' } \\
5^{\prime} \text {-CCAATCTCATCCCTCTTCA-3' }\end{array}$ \\
\hline NM_010464 & Homeobox C13 (Hoxc13) & $\begin{array}{l}5^{\prime} \text {-CTCAGTTCTTGCCTCTTC-3' } \\
5^{\prime} \text {-ACCTTGCCTATGGAGTTC-3' }\end{array}$ \\
\hline NM_010496 & Inhibitor of DNA binding $2(I d 2)$ & $\begin{array}{l}5^{\prime}-\text { GACTCGCATCCCACTATC } 3^{\prime} \\
5^{\prime}-\text { ATGCTGATGTCCGTGTTC-3' }\end{array}$ \\
\hline NM_010591 & Jun oncogene (Jun) & $\begin{array}{l}\text { 5'-CTGATTTGTAGGAATAGATACCC-3' } \\
5^{\prime} \text {-CACAGCACATGCCACTTC-3' }\end{array}$ \\
\hline NM_010659 & Keratin 1-1 (Krt1-1) & $\begin{array}{l}5^{\prime}-\text { GTCTCCAATCCCTGTGTC } 3^{\prime} \\
5^{\prime}-\text { TGTCCTTGCTCTGTTGAC-3' }\end{array}$ \\
\hline NM_008470 & Keratin 1-16 (Krt1-16) & $\begin{array}{l}5^{\prime} \text {-AATATCCACTCCTCCTCAC-3' } \\
5^{\prime} \text {-GTTGAACCTTGCTCCTTG-3' }\end{array}$ \\
\hline NM_010666 & Keratin 1-c29 (Krt1-c29) & $\begin{array}{l}\text { 5'-TCGTGGAAGAGTTAGACC-3' } \\
\text { 5' -TTAGAGGCGGAGTTCAAG-3' }\end{array}$ \\
\hline NM_010663 & Keratin 1-17 (Krt1-17) & $\begin{array}{l}5^{\prime}-\text { ACCTGACTCAGTACAAGCC-3' } \\
5^{\prime} \text {-CCTTAACGGGTGGTCTGG-3' }\end{array}$ \\
\hline BC006780 & Keratin 2-5 (Krt2-5) & $\begin{array}{l}5^{\prime}-\text { AATGTAAGCCACCAAAGCAGAACC-3' } \\
5^{\prime} \text {-GGAGGAAGTCAGAACCAGGACAG-3' }\end{array}$ \\
\hline AY028606 & Keratin 2-20 (Krt2-20) & $\begin{array}{l}5^{\prime} \text {-GAACCACTGTGACAACCTACG-3' } \\
5^{\prime} \text {-CTGCCTCAATGTCCTGCTG-3' }\end{array}$ \\
\hline NM_010703 & Lymphoid enhancer binding factor 1 (Lef1) & $\begin{array}{l}5^{\prime}-\text { GCCAGCCACCGCCGATTC-3' } \\
5^{\prime} \text {-GGCGGCGTTGGACAGATC-3' }\end{array}$ \\
\hline NM_008808 & Platelet-derived growth factor alpha (Pdgfa) & $\begin{array}{l}5^{\prime}-\text { AGACAGATGTGAGGTGAG-3' } \\
5^{\prime} \text {-ACGGAGGAGAACAAAGAC-3' }\end{array}$ \\
\hline NM_176996 & Smoothened homolog (Smo) & $\begin{array}{l}\text { 5'-AAAGTGTTTATTGTGTCATTTGTC-3' } \\
\text { 5'-GGAACTGAGATGTGAATGTAGG-3' }\end{array}$ \\
\hline NM_009170 & Sonic hedgehog (Shh) & $\begin{array}{l}\text { 5'-CATTCCTCTCCTGCTATGCTCCTG-3' } \\
5^{\prime} \text {-ATGACAAAGTGGCGGTACAAAGC-3' }\end{array}$ \\
\hline NM_011718 & Wingless related MMTV integration site 10b (Wnt10b) & $\begin{array}{l}\text { 5'-AGCGTCTTCTCTACCTACAG-3' } \\
5^{\prime} \text {-ACACAATGCCTGCTATTATCC-3' }\end{array}$ \\
\hline NM_009524 & Wingless-related MMTV integration site 5A (Wnt5a) & $\begin{array}{l}5^{\prime}-\text { CCACGAATACCAGGAAGCAAGC- } 3^{\prime} \\
5^{\prime} \text {-CCCACAAAGAACACCAAAGAGAGG-3' }\end{array}$ \\
\hline NM_011915 & Wnt inhibitory factor 1 (Wif1) & $\begin{array}{l}5^{\prime}-\text { CCACCTGAATCCAATTACATC-3' } \\
5^{\prime}-\text { TGAACAGCATTTGAACATCC-3' }\end{array}$ \\
\hline
\end{tabular}

using the NIA Array Analysis software (http://lgsun.grc. nia.nih.gov/ANOVA/, 2007; last accessed January 31, 2009) according to the recommendations published previously. ${ }^{24}$

\section{Cell Culture Experiments, Western Blot, and Real-Time PCR Analyses}

Keratinocytes from HF-derived tumors of TG mice were grown at low $(0.05 \mathrm{mmol} / \mathrm{L})$ calcium concentrations and were treated for 24 hours either with 200 to $500 \mathrm{ng} / \mathrm{ml}$ BMP-4, $200 \mathrm{ng} / \mathrm{ml}$ BMP-4, and $500 \mathrm{ng} / \mathrm{ml}$ noggin (R\&D Systems, Minneapolis, MN) or diluent control and were processed for total RNA and protein isolation. Western blot analysis of total tissue proteins obtained from the extracts of full thickness skin of TG and WT mice or from cultured tumor cells was performed, as described before. ${ }^{15,25}$ Antibody reaction was performed with rabbit polyclonal antisera against noggin, Wif-1, or Shh (R\&D
Systems, Minneapolis, MN). Real-time PCR was performed three times using iQ SYBR Green Supermix and MyiQ Single-Color Real-Time PCR Detection System (BioRad Corp., Hercules, CA). ${ }^{16}$ Differences between samples and controls were calculated using Gene Expression Macro program (Bio-Rad Corp., Hercules, CA) based on the $\Delta \Delta \mathrm{C}_{\mathrm{t}}$ equitation method, data were pooled, mean \pm SEM was calculated, and statistical analysis was performed using unpaired Student's t-test. PCR primers were designed on Beacon Designer software (Premier Biosoft International, Paolo Alto, CA; Table 1).

\section{Immunohistochemistry and in Situ Hybridization}

Frozen skin samples embedded into Tissue-Tek medium were processed for immunohistochemical protocols, as described before. ${ }^{15,25}$ Briefly, cryosections were fixed in acetone and after blocking non-specific binding, primary antibody was applied (see Table 2) following by applica- 
Table 2. List of Primary Antibodies

\begin{tabular}{llll}
\hline \multicolumn{1}{c}{ Antigen } & Host & Dilution & Manufacturer/source \\
\hline BrdU & Mouse & $1: 50$ & BD Pharmingen, Franklin Lakes, NJ \\
beta-Catenin & Mouse & $1: 100$ & Sigma, St. Louis, MO \\
Edar & Goat & $1: 100$ & R\&D Systems Inc., Minneapolis, MN \\
Keratin 14 & Rabbit & $1: 1000$ & Babco, Berkeley, CA \\
Ki-67 & Rat & $1: 1000$ & Dako Denmark, Glostrup, Denmark \\
Lef1 & Rabbit & $1: 100$ & R\&D Systems Inc., Minneapolis, MN \\
Lhx2 & Goat & $1: 250$ & Santa-Cruz Biotechnology, Santa-Cruz, CA \\
Loricrin & Rabbit & $1: 150$ & R\&D Systems Inc., Minneapolis, MN \\
N-CAM & Rat & $1: 500$ & Chemicon International Inc., Temecula, CA \\
pSmad1/5 & Rabbit & $1: 1000$ (Tyramide amplification) & Chemicon International Inc., Temecula, CA \\
Shh & Rabbit & $1: 100$ & R\&D Systems Inc., Minneapolis, MN \\
Trichohyalin (AE15) & Mouse & $1: 100$ & Gift from T.T. Sun (NYU) \\
Wif1 & Goat & $1: 1000$ (Tyramide amplification) & R\&D Systems Inc., Minneapolis, MN \\
Wnt 10b & Goat & $1: 100$ & R\&D Systems Inc., Minneapolis, MN \\
\hline
\end{tabular}

tion of the corresponding fluorescein isothiocyanate-, tetramethylrhodamine B isothiocyanate-, or biotin-labeled secondary antibody (Jackson ImmunoResearch, West Grove, PA) or by visualizing the reaction product using the tyramide amplification kit (Perkin Elmer/NEN, Boston, MA) or the MOM basic kit (Vector Laboratories, Burlingame, CA). Cell nuclei were visualized with 4'6'-diamidino-2-phenylindol. Alkaline phosphatase activity was visualized using histo-enzymatic reaction. In situ hybridization with Dig-labeled riboprobes for hGH-polyA, noggin, keratin 15, Wif-1, Shh, Ptch1/2, Gli 1, and cyclin D1/D2 was performed, as described previously. ${ }^{14,23,26}$

\section{Cell Transfection Experiments}

HaCaT keratinocytes were grown in Dulbecco's modified Eagle's medium supplemented by $10 \%$ fetal bovine serum until $60 \%$ to $70 \%$ confluent. Cells were incubated for 6 hours and 24 hours with $200 \mathrm{ng} / \mathrm{ml}$ rhBMP-4 (R\&D Systems) or diluent control, as described before. ${ }^{15,25}$ The Wif1-Luc and Shh-Luc reporter plasmids containing human Wif1 and Shh promoters (nucleotides -1512 to +6 of human Wif1 gene and nucleotides 3347 to 1548 of a 1.9-kb human Shh promoter sequence, respectively) ${ }^{27,28}$ and PGVB2L-Luc control vector were used for transient co-transfection experiments. Plasmid vectors containing constitutively active BMP receptors (BMPR-IA or Alk3QD and BMPR-IB or Alk6QD) as well as Smad1/5 expressing plasmids under pCMV promoter ${ }^{29}$ (kindly provided by Prof. K. Funa) were used for transfection of HaCaT keratinocytes using Lipofectamine 2000 reagent (Invitrogen, San Diego, CA), as described previously. ${ }^{15}$ BMP-responsive plasmid vector 3GC2-Lux containing three repeats of GC-rich sequence derived from the proximal region of the Smad6 promoter were used as positive control. ${ }^{29}$ In all experiments, the internal control plasmid was used to compensate variable transfection efficiencies. All assays were repeated three times using Dual-Luciferase Reporter Assay System (Promega, Madison, WI), data were pooled, mean \pm SEM was calculated, and statistical analysis was performed using unpaired Student's $t$-test.

\section{Results}

\section{K14-Driven Noggin Overexpression Results in} Epidermal Hyperplasia, Progressive Hair Loss, and Formation of Trichofolliculoma-Like Tumors

To define a role of BMP signaling in skin development and tumorigenesis, TG mice overexpressing BMP antagonist noggin under keratin 14 (K14) promoter were generated using FVB/NJ mice as a background strain, which is more susceptible to experimentally induced skin carcinogenesis. ${ }^{30}$ Transgenic construct containing mouse noggin cDNA and human $\mathrm{K} 14$ promoter that directs gene expression to the basal epidermal layer and HF outer root sheath was generated as described previously ${ }^{23}$ (Figure $1 \mathrm{~A})$. Western blot analysis of protein extracts from dorsal skin of TG mice showed increased levels of the $64-\mathrm{kDa}$ noggin protein compared with WT skin (Figure 1A). By in situ hybridization with the probe specific to the human growth hormone polyadenylation sequence, cells expressing TG construct were seen in the basal layer of epidermis, HF outer root sheath, and sebaceous gland, and no such expression was seen in the WT mice (Figure 1A).

Newborn TG mice could not be distinguished from their WT littermates until P10 to P11, when TG mice began to develop hair loss, which became more evident in adult mice (Figure 1B). TG mice showed some similarities, such as lack of zig-zag hairs and hyperplasia of nails, to the skin phenotype seen in K14-noggin mice generated using chicken noggin cDNA previously. ${ }^{31}$ However, in contrast to those mice, ${ }^{31} \mathrm{TG}$ mice generated here showed formation of the multiple hair follicle-derived tumors (Figure 1, C and D). Despite relatively normal process of HF morphogenesis (see supplemental Figure S1 A at http://ajp.amjpathol.org), TG mice as early as at P14 showed formation of new epithelial buds growing from the upper and middle portions of the HF outer root sheath and increased alkaline phosphatase activity in the adjacent cells of the HF connective tissue sheath and interfollicular dermis (Figure 1C). Interestingly, neoplastic process was seen only in non-guard (secondary) HFs, 
A
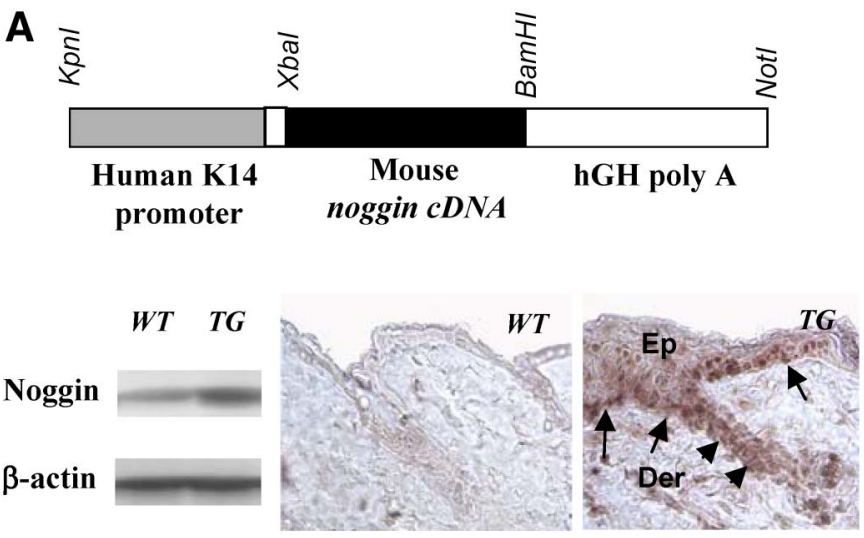

C

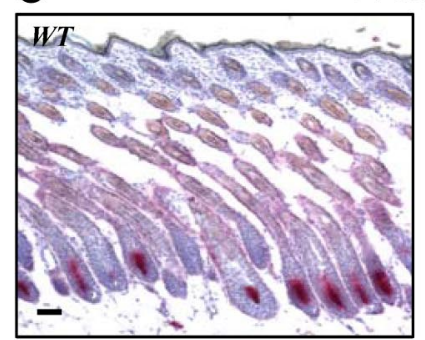

14 day-old

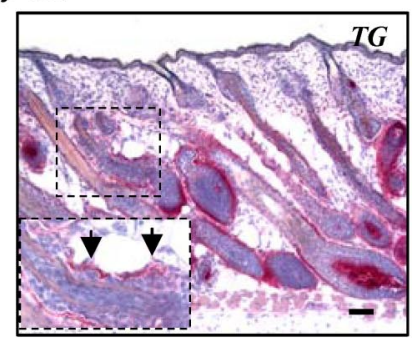

D

6 month-old

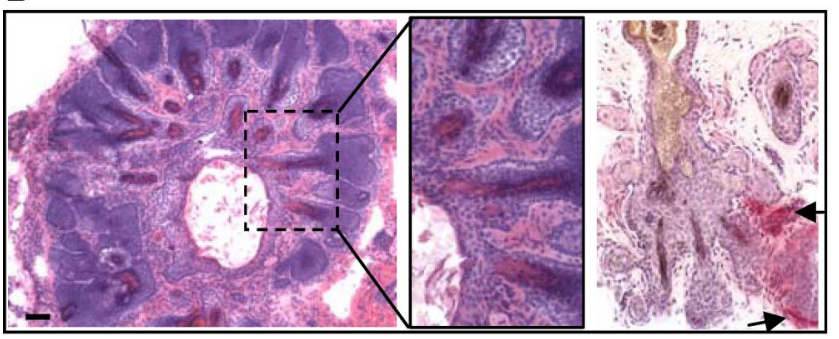

B 6 week-old

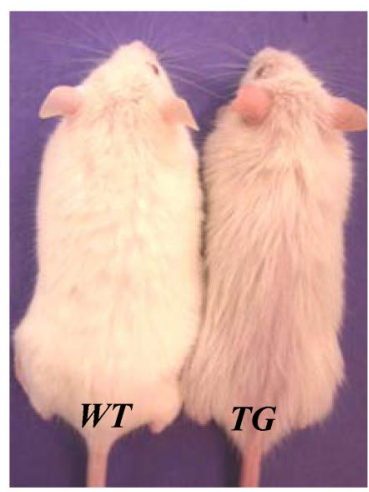

6 month-old

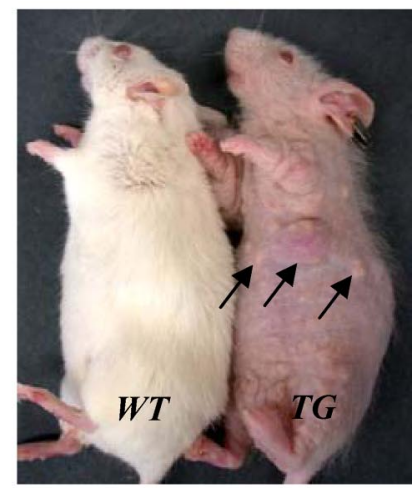

30 day-old

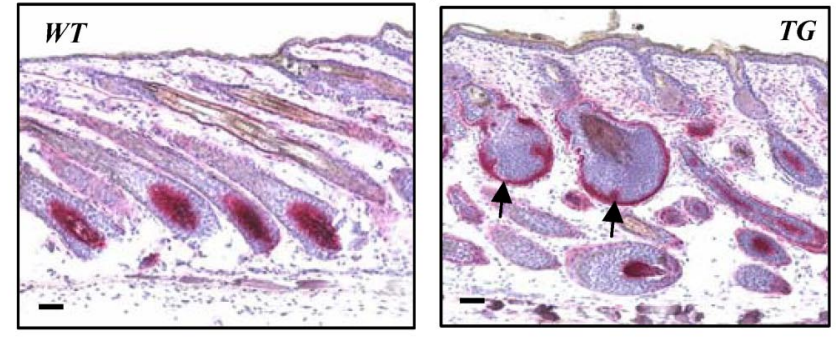

Human trichfolliculoma

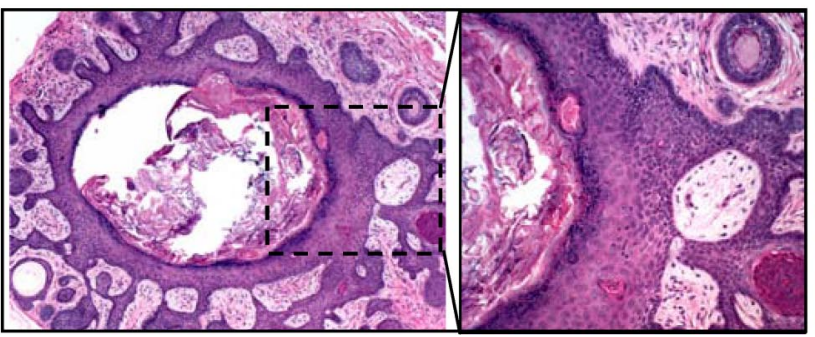

Figure 1. Epidermal hyperplasia, progressive hair loss, and formation of the hair follicle-derived tumors in K14-Noggin mice. A: The K14-Noggin construct usec to generate transgenic mice. Western blot analysis of the $64 \mathrm{kDa}$ Noggin protein in skin of 8- to 9-week-old TG versus wild-type (WT) mice. In situ hybridization: expression of transgene in basal layer of the epidermis (arrows) and HF outer root sheath (arrowheads). B: Phenotypes of 6-week-old and 6-month-old K14-Noggin mice, skin tumors are shown by arrows. C: Histological analysis of wild-type and TG skin at different time points of postnatal development by histoenzymatic alkaline phosphatase visualization. First signs of tumor development at P14 (left panel, epithelial outgrowth from the outer root sheath in TG mice is shown by arrows, inset). Formation of large HF-derived tumors at P30 (right panel, arrows). D: In 6-month-old mice, HF-derived tumors contain central cysts, multiple hair shafts (H\&E staining, left panel, inset), and alkaline phosphatase-positive stroma (left panel, arrows). Morphology of human trichofolliculoma (H\&E staining, right panel).

while guard (primary) HFs were not affected (data not shown). Histological analysis of TG skin during first anagen-catagen transition between $\mathrm{P} 15$ to $\mathrm{P} 18$ revealed that affected HFs failed to regress and remained in anagenlike phase, whereas in WT skin all HFs entered into catagen phase followed by telogen (see supplemental Figure S1 B at http://ajp.amjpathol.org). During P26 to P40, HFs in TG mice showed outgrowth of additional epithelial buds from the outer root sheath leading subsequently to the formation of large HF-derived tumors (Figure 1C).

TG mice also exhibited generalized hair loss by 4 months of age, and 100\% 6-month-old mice showed macroscopically visible skin tumors distributed randomly all over the dorsal and ventral skin surface (Figure 1D). Histological analysis of tumors revealed as many as 10 to 15 densely packed and disoriented hair follicle-like structures growing out of single focal source with tendency to form an epithelioid cyst containing keratinized substance in the center (Figure 1D). Tumors contained hyperplastic matrix cells, rudimentary hair shafts, were surrounded by mesenchymal cells with strong alkaline phosphatase activity and morphologically resembled human trichofolliculomas (Figure 1D).

In contrast to WT mice, adult TG mice also showed enlargement of the sebaceous glands (data not shown), increase in thickness and number of proliferating Ki-67positive cells in the interfollicular epidermis $(P<0.05)$, while expression of the keratinocyte differentiation markers (loricrin, involucrin, and filaggrin) was not changed (see supplemental Figure S1, C-G at http://ajp.amjpathol. org). Also, TG mice showed strongly decreased expression of phospho-Smad1/5/8 in the epidermis, sebocytes, outer root sheath, bulge, and in HF-derived tumors, compared with the corresponding skin and HF compartments of WT mice (see supplemental Figure S1, H-M at http:// ajp.amjpathol.org). Marked decrease of the pSmad1/5/8 
expression was also seen in human trichofolliculomas compared with normal anagen HFs (see supplemental Figure S1, N and O, at http://ajp.amjpathol.org). These similarities strongly suggested that alterations in BMP signaling pathway may contribute to the formation of human trichofolliculoma, while K14-noggin mice provide an instructive model for studying mechanisms underlying its formation.

\section{Global Microarray Analysis of the Follicular Tumors in K14-Noggin Mice Reveals Alterations in Cell Cycle Machinery and Marked Increase of Pro-Oncogenic Signaling}

To characterize the molecular signature of the HF-derived tumors in TG mice, tissue samples were obtained from the hair matrix of small and intermediate anagen $\mathrm{VI}$ HFs of wild-type mice and from the epithelium of HFderived tumors of TG mice using the laser capture microdissection and were processed for microarray and realtime PCR analyses, as described previously ${ }^{16}$ (Figure 2 A). Microarray and real-time PCR analyses of the hair matrix of WT HFs and HF-derived tumors of TG mice showed twofold or higher changes in expression of 390 genes encoding the adhesion/extracellular matrix molecules, cell cycle/apoptosis, and cytoskeleton/cell motility markers, molecules involved in the control of cell differentiation, metabolism, signaling, and transcription (Figure 2 B, and see supplemental Tables S1 and S2 at http://ajp.amjpathol.org).

In contrast to WT mice, HF-derived tumors showed marked increase in expression of genes encoding the selected components of signaling pathways implicated in cutaneous tumorigenesis (Wnt, hedgehog, platelet derived growth factor-A/B, Ras, etc), while expression of genes that are implicated in inhibition of cell proliferation (Igfbp4, Bmp8a, Id2, Id4) decreased (Figure 2B, see supplemental Tables S1 and S2 at http://ajp.amjpathol.org, data not shown). In contrast to hair matrix of WT mice, expression of cyclins D2, M3, and F was increased in the tumors, phosphatase and tensin homolog (PTEN) expression remained unchanged, while expression of the selected HF-specific keratins and trichohyalin decreased, suggesting alterations of cell proliferation/differentiation in the neoplastic keratinocytes (Figure 2B and C; see supplemental Tables S1 and S2 at $h$ ttp://ajp.amjpathol.org; data not shown).

By real-time PCR, HF-derived tumors in TG mice also showed down-regulation of transcription factors involved in the control of hair shaft-specific differentiation (Lef1, Msx2, Hoxc13; Figure 2B, see supplemental Tables S1 and S2 at http://ajp.amjpathol.org). In addition, expression of Edar and neural cellular adhesion molecule proteins increased in the tumor epithelium and mesenchyme, respectively, compared with the HFs of WT mice (Figure 2D). Whereas mechanisms underlying a crosstalk between BMP signaling and other regulatory pathways controlling cell proliferation in HF-derived tumors remain to be further clarified, strong differences in expression of the selected components of the pro-onco- genic signaling pathways (Wnt, Shh) and cell cycle-associated genes between WT and TG mice suggested their involvement in neoplastic transformation of the HF keratinocytes and tumorigenesis.

\section{Tumors in K14-Noggin Mice Show Stage- Dependent Differences in the Expression of the Components of the Wnt and Shh Signaling Pathways}

To further explore the role for the Wnt and Shh signaling pathways in the control of tumor development in TG mice, the expression of key Wnt and Shh signaling components and selected targets was compared between WT HFs and tumors at distinct stages of their formation (initiation phase versus fully developed tumors). Both Wnt and Shh pathways are essential for HF development and cycling [for review, see ${ }^{32}$ ], and, if abnormally activated, result in the development of a number of epithelial tumors. ${ }^{26,33-38}$

Interestingly, cells localized at the tumor placodes showed expression of the keratin $15 \mathrm{mRNA}$ and Lhx2 protein, markers of the epithelial stem cells, 39,40 while their expression in fully developed tumors strongly decreased and was seen only in clusters of cells at the tumor periphery (Figure 3, A and B). Keratinocytes of the tumor placodes also showed increased expression of the Wnt10b, Lef1, and nuclear $\beta$-catenin compared with the cells of fully developed tumors (Figure 3, A and B) and to the bulge cells of normal anagen HFs (data not shown). However, consistently with microarray and RT-PCR data (Figure 2B), expressions of Wif1 mRNA and protein were markedly reduced in the tumor placodes and fully developed tumors compared with the normal bulge and hair matrix keratinocytes (Figure $3, A$ and $B$ ), suggesting its antitumorigenic effects in normal HF stem cells and/or their progenies.

In contrast to the components of Wnt signaling pathways, transcripts for Shh were not expressed in the tumor placodes, while Ptch1, Ptch2, and Gli1 mRNAs showed expression levels similar to the fully-developed tumors (Figure 3, C and D). However, expression of the Shh markedly increased in fully developed tumors compared with the tumor placodes (Figure 3, C and D) and to the hair matrix of normal anagen HFs (not shown). Consistently with these data, transcripts for Cyclin D1 and Cyclin D2 serving as the Wnt and Shh targets, ${ }^{41}$ were seen in the tumor placodes and their expressions increased in fully developed tumors (Figure 3, C and D). These data suggested that the components of Wnt signaling pathway may contribute to the initiation of tumors in K14-Noggin mice, while Shh signaling pathway may contribute to further tumor progression.

\section{Treatment of K14-Noggin Mice with the Wnt and Shh Antagonists Results in Stage-Dependent Inhibition of the Tumor Initiation and Progression}

To better define the requirement for Wnt and Shh signaling for the development of HF-derived tumors, in vivo pharmacological studies were performed using the corresponding Wnt and Shh inhibitors Aptosyn and cyclo- 
A

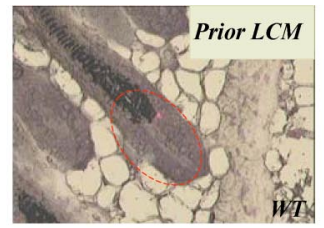

B

Overexpressed genes (258)

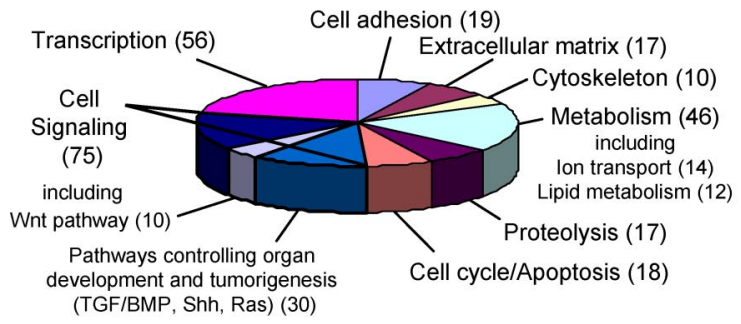

Cell cycle/Apoptosis

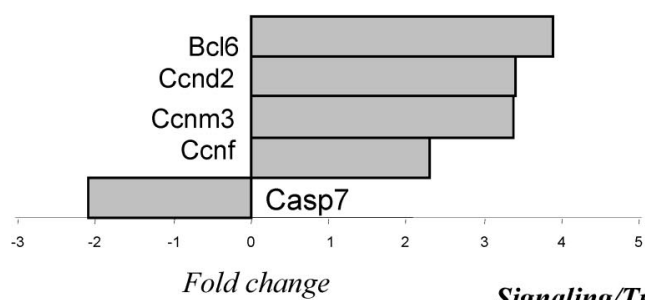

Signaling/Transcription

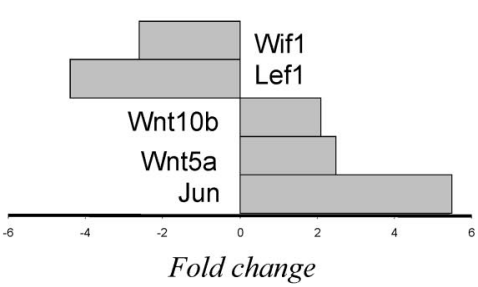

\section{C}

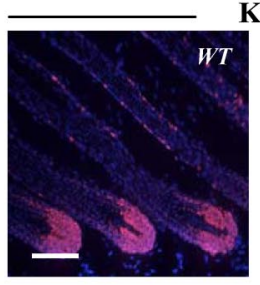

Ki67
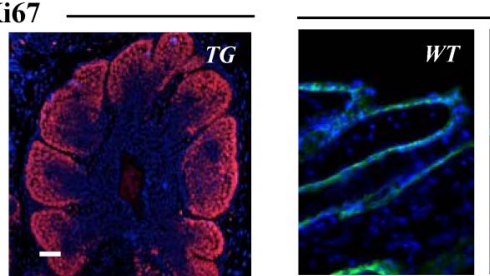

D
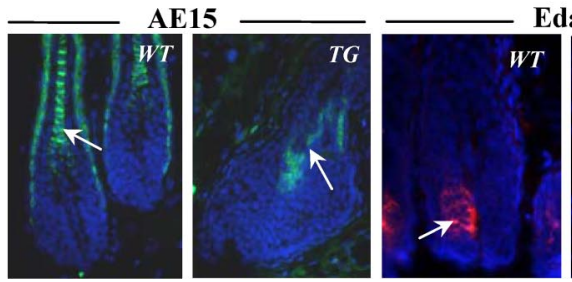

Edar
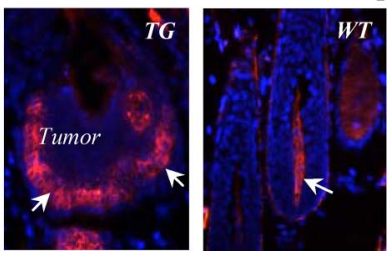

N-CAM

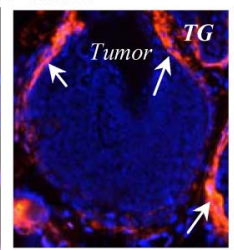

Figure 2. Hair follicle-derived tumors from TG mice show alterations in expression of cell cycle-associated genes and genes encoding pro-oncogenic molecules Skin was harvested, and cryosections were processed for laser-capture microdissection (LCM), RNA isolation and amplification, microarray, and real-time PCR analyses, and for immunohistochemistry. A: HFs of wild-type (WT) mice and HF-derived tumors of TG mice before and after LCM. B: Diagrams showing the ontology of over- and underexpressed genes and real-time PCR analysis of genes differently expressed in the tumors versus normal hair matrix cells. C: Ki-67 expression in normal HFs and HF-derived tumors (left panel). Expression of Keratin 14 in the epidermis and HFs of wild-type and TG mice (right panel, arrows). D: Decrease in AE15 expression in the tumors of TG mice (left panel, arrow) versus normal anagen HFs of wild-type mice. Increase of Edar and N-CAM expression (central and right panels, respectively) in the tumor epithelium and mesenchyme of TG mice (arrows) versus wild-type HFs.

pamine [reviewed $\mathrm{in}^{4,42}$ ]. To define whether inhibition of the Wnt and Shh signaling could affect the initiation and growth of the tumors, TG mice were treated either with Aptosyn or cyclopamine daily subcutaneously from post- natal day 10 (P10) and skin was harvested on P19, P21, and $P 28(9,11$, and 18 days after beginning of treatment, respectively). In contrast to the vehicle-treated TG mice, mice treated by the Wnt antagonist Aptosyn showed 
A
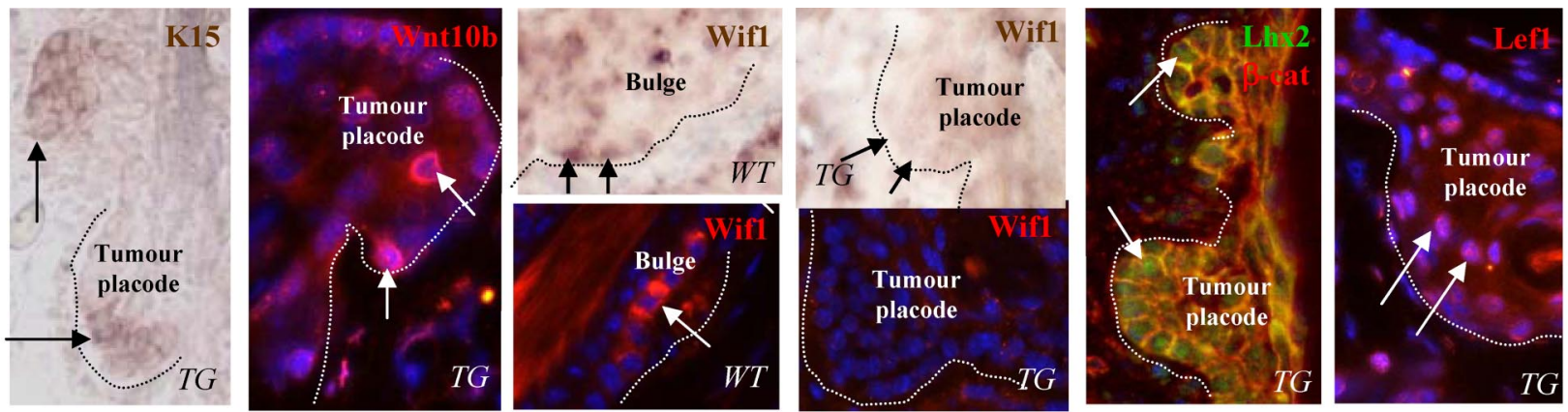

B
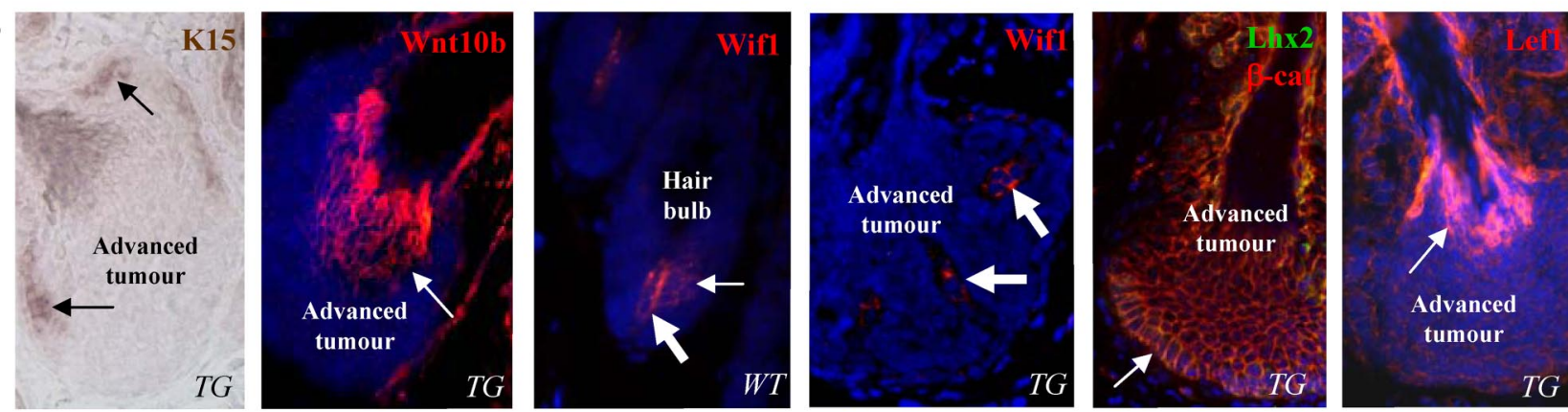

C
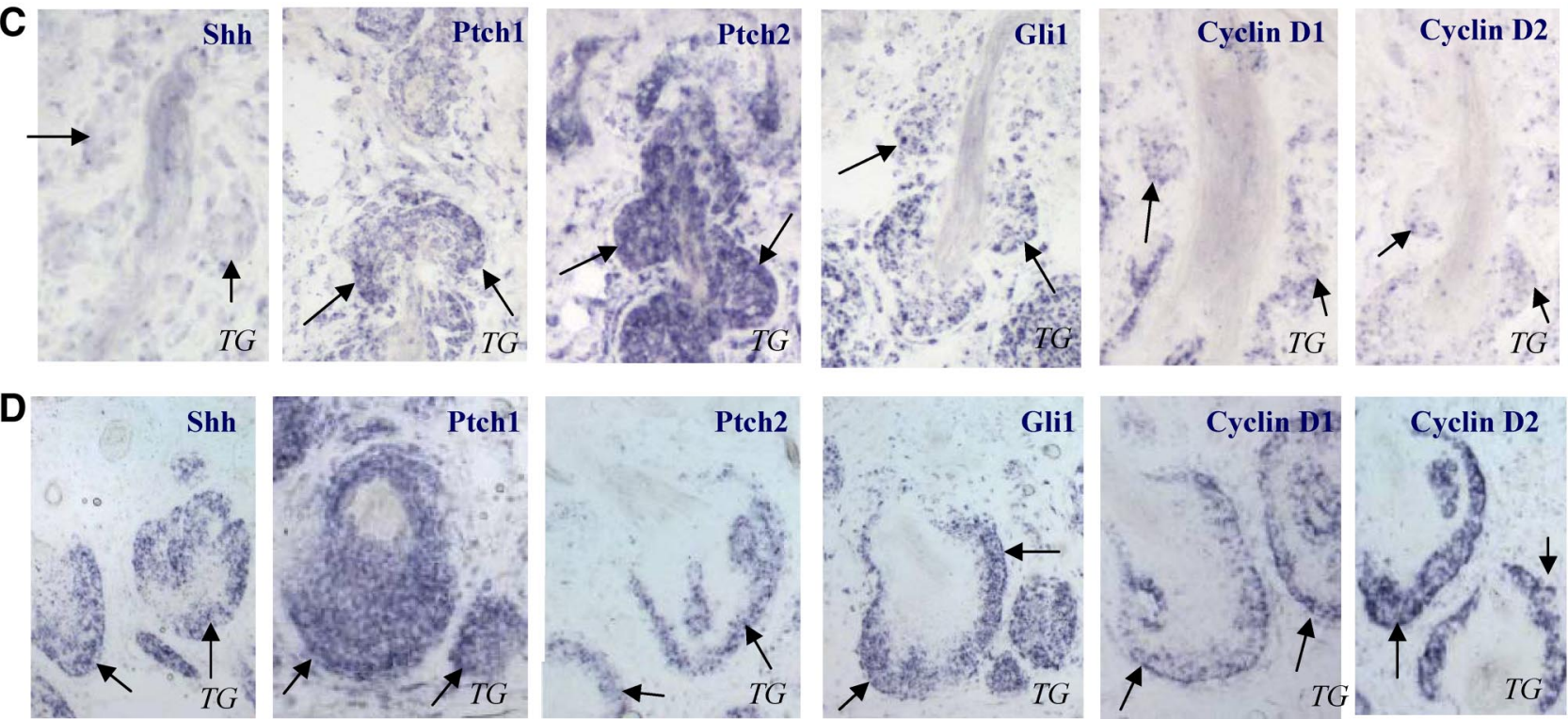

Figure 3. Stage-dependent expression of the components of Wnt and Shh pathways in the HF-derived tumors of K14-Noggin mice. Back skin of wild-type (WT) and TG mice was processed for RNA in situ hybridization or immunohistochemistry. A: Expression of the stem cell markers and components of Wnt pathway at the initiation phase of tumor formation. Expression of the K15 and Wif1 mRNAs, Wnt10b, Wif1, Lhx2, $\beta$-catenin, and Lef1 proteins in tumor placodes (arrows). Marked decrease of Wif1 mRNA and proteins expression in tumor placodes (dotted line) compared with the bulge, dermal papilla, and hair matrix (arrows) of anagen VI HF in wild-type mice. B: Expression of the components of Wnt pathway in fully developed tumors. Expression of K15 mRNA in distinct groups of cells at the tumor periphery (left image, arrows). Expression of Wnt10b and Lef-1 in differentiating tumor cells (arrows). Lack of Wif1, Lhx2, and nuclear $\beta$-catenin in cells of fully developed tumors (arrows). Wif1 expression in the dermal papilla of anagen VI HFs and in tumor mesenchyme is shown by large arrows. C: Expression of the components of Shh pathway and cyclins D1/D2 at the initiation phase of tumor formation. Lack of Shh expression and decreased expression of cyclin D1 and D2 in tumor placodes (arrows). Ptch1, Ptch2 and Gli1 expression in tumor placodes (arrows). D: Expression of the components of Shh pathway and cyclins D1/D2in fully-developed tumors. Strong expression of the Shh, Ptch1, Ptch2, Gli1, cyclin D1 and D2 at the tumor base (arrows).

significant $(P<0.05)$ decrease in the number of HFs with new outgrowths arising from the outer root sheath accompanied by the decrease of nuclear $\beta$-catenin staining in the HF keratinocytes, thus suggesting inhibition of the tumor initiation (Figure 4A).

However, treatment of TG mice with Shh inhibitor cyclopamine did not show any effects on tumor initiation and the formation of new outgrowths from the outer root sheath (data not shown). Instead, cyclopamine treatment resulted in significant $(P<0.001)$ retardation of tumor progression in TG mice compared with controls (Figure 4 B). Inhibition of tumor growth after cyclopamine treatment was accompanied by decrease in expression of the Gli1 in the HF epithelium, as well as by down-regulation of the alkaline phosphatase activity in adjacent mesenchyme indicating that cyclopamine may also affect epithelial- 

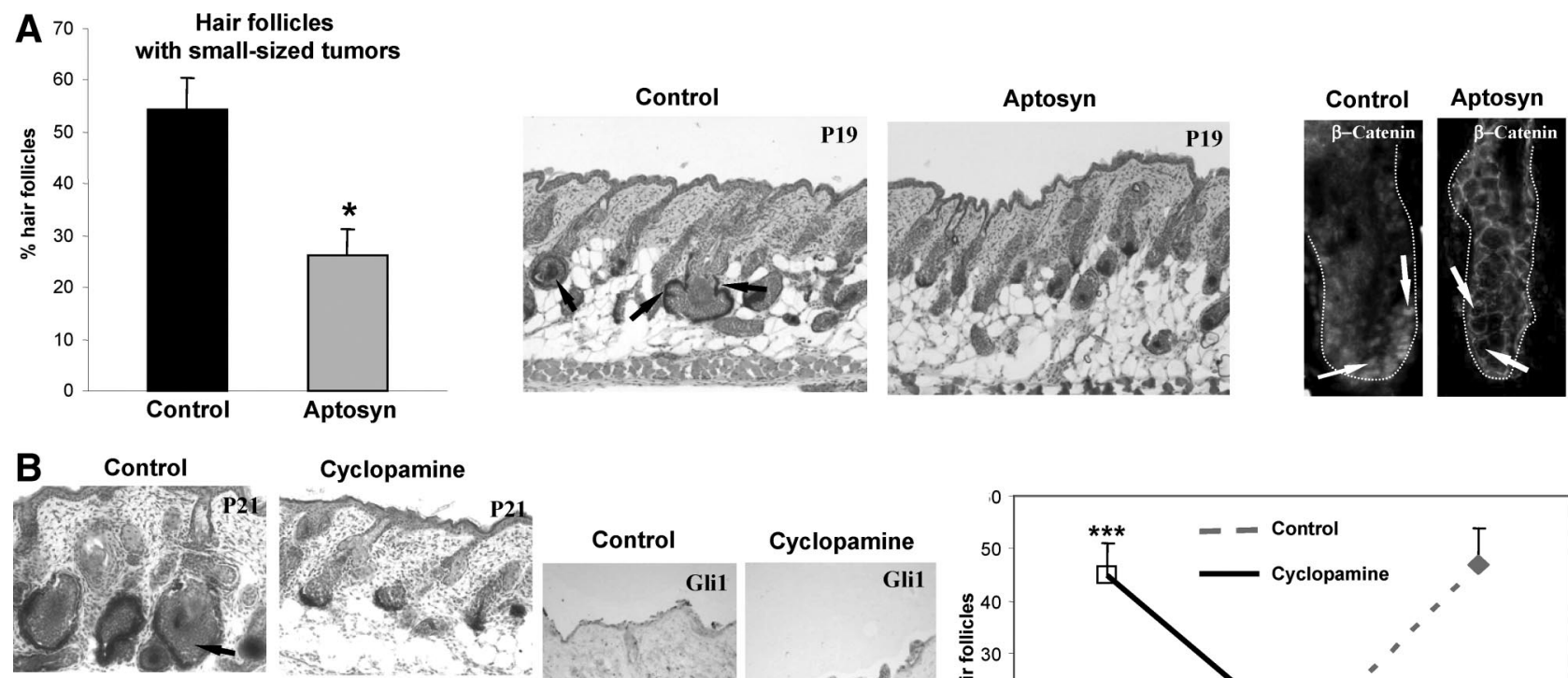

\section{Cyclopamine}
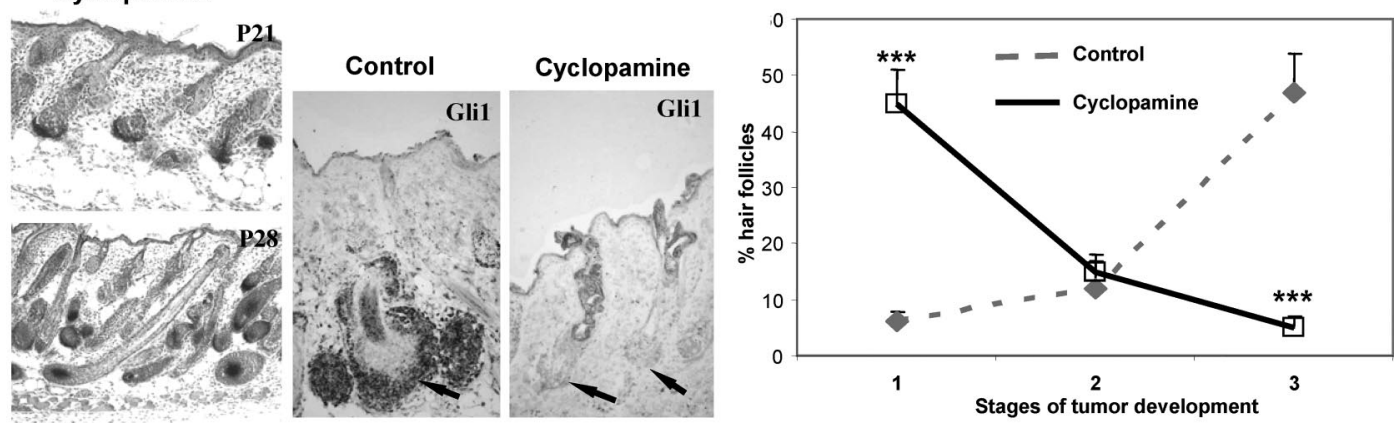

Figure 4. Treatment with the Wnt and Shh inhibitors differentially affects tumor formation in K14-Noggin mice. Back skin of Aptosyn- or cyclopamine-treated and nontreated mice was harvested at P19, P21, and P28, and processed for histoenzymatic visualization of alkaline phosphatase and histomorphometric analysis of HF-derived tumors. Statistical analyses were performed by using Student's $t$-test. A: Significant decrease $\left({ }^{*} P<0.01\right)$ in number of HFs with small tumors after Aptosyn treatment versus control. In control skin, small-sized HF tumors are shown by arrows (middle panel). In control HFs, nuclear $\beta$-catenin is seen in keratinocytes of the outer root sheath (left panel, arrows). In Aptosyn-treated mice, expression of nuclear $\beta$-catenin in the HF keratinocytes is strongly decreased (right panel, arrows). HFs are demarcated by dotted line. B: Significant decrease $\left({ }^{* * * *} P<0.001\right)$ in number of HFs bearing large and medium-sized tumors in TG mice treated by cyclopamine versus control (left and right panels, arrows). Decreased Gli1 expression in the HF keratinocytes after cyclopamine treatment (central panel, arrows).

mesenchymal interactions in developing tumors (Figure 4 B). These data suggested that Wnt and Shh signaling are differentially involved in the control of tumor initiation and progression, respectively, and may serve as targets for the BMP regulation in the HF keratinocytes.

\section{BMP Signaling Stimulates the Wif1 Expression and Promoter Activity and Inhibits Shh Expression in Vitro}

To further understand the mechanisms underlying the cross-talk between the BMP, Wnt and Shh signaling pathways in the development of HF-derived tumors and to determine whether BMP signaling is indeed involved in the control of the expression of Wif1 and Shh, tumor cells were isolated from TG mice and were cultured in presence of different concentrations (200 ng/ml and $500 \mathrm{ng} / \mathrm{ml}$ ) of BMP-4 protein. By real-time PCR and Western blot analysis, marked increase of the Wif1 mRNA and protein and decrease of the Shh transcripts and protein were seen in tumor cells within 24 hours after addition of both concentrations of BMP-4 (Figure 5, A and B). However, these effects were significantly lowered by co-administration of the noggin protein into the culture medium (Figure 5A).

To assess whether BMP signaling is capable of influencing the activities of the Wif1 and Shh promoters, HaCaT keratinocytes were transfected with the corre- sponding reporter plasmids containing human Wif1 or Shh promoters, respectively ${ }^{27,28}$ or with pGVB2L-Luc control vector. Cells were also co-transfected with vectors containing one of the constitutively active BMP receptors and/or pCMVSmad1/Smad5 vectors. ${ }^{29}$ Cell transfection with the Alk3QD and pCMVSmad1 vectors resulted in about 2.5-fold increase of Wif1-Luc activity versus control (Figure 5C). However, lack of any effects was seen on the Shh-Luc activity (Figure 5C). These data suggested that BMP signaling positively regulates activity of the Wif1 promoter and may indeed suppress tumor initiation in vivo via stimulating the Wif1 expression and antagonizing Wnt signaling pathway. These data also suggested that negative effects of the BMP signaling on Shh likely require the involvement of other factors directly regulating its expression in keratinocytes.

\section{Discussion}

In this paper, we show that BMP signaling possess a potent antitumor activity in the HF and prevents the development of follicular tumors, at least in part, via modulating the activity of pro-oncogenic Wnt and Shh signaling pathways (Figure 1). These data are consistent with previous observations demonstrating that BMP signaling operates as a potent tumor suppressor in the epidermis and $\mathrm{HF}^{10,12,18,43}$ and show that antitumor effects of BMPs in skin strongly depend on the local concentrations of the 
A
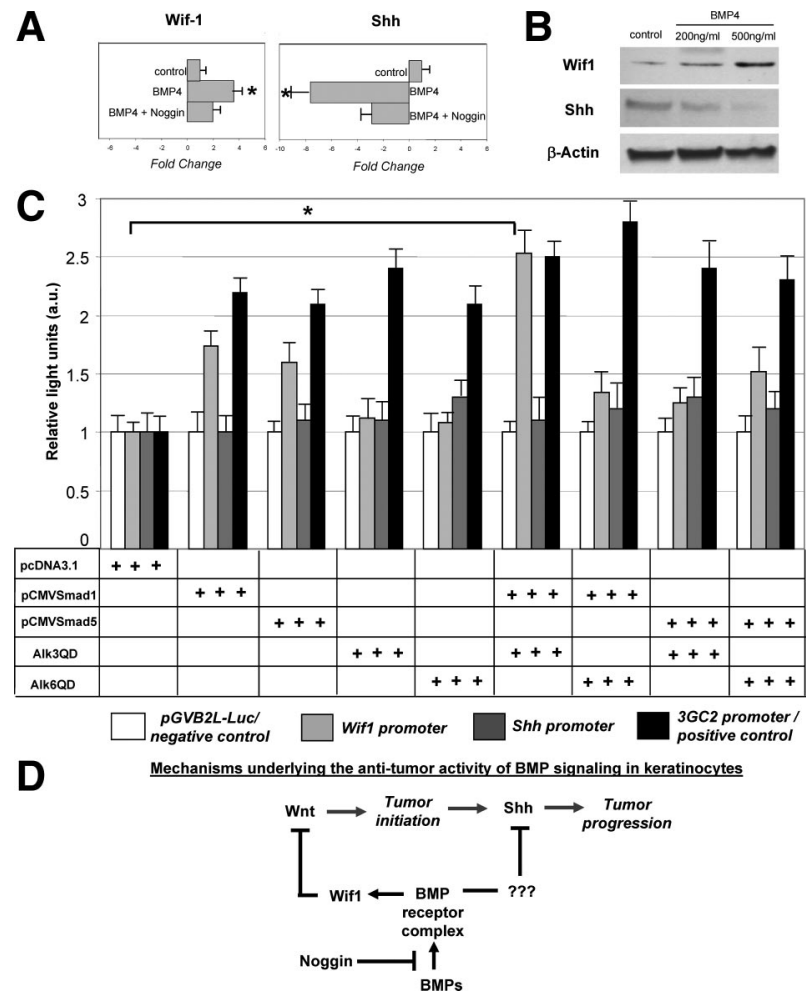

Figure 5. BMP signaling modulates Wif1 and Sh expression in cultured tumor cells and stimulates Wif1 promoter activity in HaCaT keratinocytes. A B: The tumor cells were isolated and cultured with presence of 200 to 500 $\mathrm{ng} / \mathrm{ml} \mathrm{BMP-4}$ or $200 \mathrm{ng} / \mathrm{ml} \mathrm{BMP-4}$ and $500 \mathrm{ng} / \mathrm{ml} \mathrm{Noggin}$. Cells were harvested 48 hours after treatment, and RNA and protein were isolated and processed for real-time PCR and Western blot analyses. Results show marked increase of Wif1 and decrease of Shh mRNAs $(P<0.05)$ and proteins after BMP- 4 treatment. Effects of BMP-4 on the expression of the Wif 1 and Shh transcripts are abrogated by Noggin (A). C: Effects of co-transfection with vectors containing constitutively active BMPR-IA (Alk3QD), BMPR-IB (Alk6QD), pCMVmSmad1, and/or pCMVSmad5 on transcription of the Wif1Luc and Shh-Luc reporter plasmids containing human Wif1 and Shb promoter regions and pGVB2L-Luc (negative control). D: Scheme illustrating mechanisms of the effects of BMP signaling on distinct stages (initiation and progression) of tumor formation.

BMP inhibitor noggin, which may significantly compromise tumor suppressor function of the BMPs.

Similar effects of noggin are also described in the intestinal epithelium, in which noggin overexpression results in a formation of ectopic crypts and development of a phenotype resembling juvenile polyposis. ${ }^{44}$ Interestingly that another BMP antagonist, gremlin, is widely expressed in many different forms of cancers including basal cell carcinoma, and is also capable of promoting proliferation of tumor cells inhibited by BMPs. ${ }^{22}$ Collectively, these data suggest that BMP antagonists may significantly affect intrinsic antitumor potential in skin and their expression and activity appears to be critical for the normal versus neoplastic fate decision in keratinocytes.

Our data demonstrating a marked decrease of pSmad1/ 5/8 expression in human trichofolliculoma that show striking similarity in morphology to the HF-derived tumors of K14-noggin mice suggest the involvement of BMP signaling in the development of this type of neoplasia in human skin (Figure 1). However, it remains to be determined whether trichofolliculoma development in humans is associated with mutations in genes encoding the com- ponents of BMP signaling pathway, or, similar to K14noggin mice, its development is regulated by biochemical changes at the levels and/or activity of the BMP antagonists.

We provide here evidence that inhibition of BMP signaling by noggin results in abnormal activation of at least two pro-oncogenic pathways in the HFs, namely the Wnt and Hedgehog signaling (Figure 2, Figure 3). Moreover, we show that both pathways contribute to the formation of tumors in K14-noggin mice, however, their involvement in the control of neoplastic process show striking stagedependent differences with predominant effects of the Wnt signaling on the tumor initiation and of the Shh signaling on the tumor progression, respectively (Figure 4). Given that Wnt and Shh signaling pathways contribute to the development of many tumors outside of the skin (gastrointestinal tract, breast, brain, etc), these data may be highly applicable for the pathobiology of a large number of cancers. ${ }^{45-48}$ These data are also consistent with recent observations demonstrating an essential role for cross-talk between the Wnt and Shh signaling pathways during the development of basal cell carcinoma. ${ }^{38}$

Our data showing the involvement of Wnt signaling pathway in the formation of trichofolliculomas are consistent with previous observations demonstrating that continuous activation of $\beta$-catenin signaling in the HF keratinocytes results in conversion of HFs into this benign tumor. ${ }^{45}$ Recent data reveal that activity of $\mathrm{Wnt} / \beta$-catenin signaling in keratinocytes is regulated at several levels including (PTEN) homolog-Akt-mediated control of $\beta$-catenin stabilization and Vitamin $\mathrm{D}$ receptor-dependent regulation of $\beta$-catenin transcription. ${ }^{43,46,47}$

Our data show that in addition to the previously proposed the BMP-(PTEN) homolog-Akt-axis, ${ }^{43,46}$ the activity of Wnt pathway in the HF is also regulated by the BMP signaling at the level of extracellular Wnt antagonist Wif1, which operates as a potent tumor suppressor in other organs (lungs, prostate, breast, etc). ${ }^{48}$ Wif1 promoter contains numerous Smad1-binding sites, ${ }^{27}$ and our data demonstrating positive effects of BMP signaling on the Wif1 expression and promoter activity in keratinocytes (Figure 3; Figure 5) are consistent with recently published results obtained on dermal papilla cells. ${ }^{49}$ Thus, these data suggest a novel mechanism underlying the tumor suppressor activity of BMP signaling pathway during the development of cutaneous tumors (Figure 5D) and may also be useful for better understanding the pathobiology of a number of neoplasm outside of the skin associated with alterations in the Wif1 activity. ${ }^{48}$

In our studies, tumor placode cells that lack of pSmad1/5/8 and Wif1 expressions are also positive for the stem cell markers K15 and Lhx2 (Figure 3). Several observations show that Wnt signaling may promote the initiation of neoplastic process in many types of epithelial tumors via modulating the activity of stem cells. $^{34,35,37,45,47,50,51}$ It is also shown that BMP signaling inhibits proliferation of adult HF stem cells, while conditional ablation of the Bmpr1a gene triggers HF stem cells to proliferate leading to tumorigenesis. ${ }^{43,46,52}$ However, it remains to be further clarified whether noggin-dependent 
modulation of BMP signaling directly affects Wif1 expression in the HF stem cells thus contributing to their reprogramming toward a neoplastic phenotype, or these changes occur at the level of transient amplifying cells during their differentiation pathway toward hair matrix keratinocytes.

We also show here that hedgehog signaling is likely not involved in the control of tumor initiation and, instead, contribute to the tumor progression in K14-noggin mice (Figure 3, Figure 4, Figure 5). These data are consistent with recent observations demonstrating the cross-talk between Shh and Wnt signaling during the development of basal cell carcinoma ${ }^{38}$ and confirm previous data showing positive regulation of the Shh expression by BMP antagonists. ${ }^{14,22}$ It is unclear, however, which mechanisms may be involved in mediating the effects BMP on the Shh expression in keratinocytes. Edar signaling may serve as one of the candidates in mediating the cross talk between BMP and Shh pathways in trichogenic tumors: Edar expression is increased in HF-derived tumors of K14-noggin mice (Figure 2), Edar has been shown to be a direct target for down-regulation by BMP signals, ${ }^{53}$ and, in turn, is capable of positively regulating Shh expression. ${ }^{54}$

It remains to be further determined whether other regulatory molecules, whose expression is changed in tumors (Figure 2, see supplemental Tables S1 and S2 at http://ajp.amjpathol.org), are also capable of modulating a cross-talk between the BMP and Shh signaling pathways during the neoplastic process in the HF. Furthermore, potential roles for a large number of genes that show differences in expression between hair matrix of wild-type and tumors in K14-noggin mice (see supplemental Tables S1 and S2 at http://ajp.amjpathol.org) remain to be further defined in terms of their contribution to the development of HF neoplasia in noggin transgenics. Also, additional efforts are required to understand what underlie the differences in skin phenotypes between K14noggin mice generated using distinct transgenic constructs containing mouse and chicken noggin cDNAs (Figure 1). ${ }^{31}$ Perhaps, levels of transgene expression and differences in activity of the mouse and chicken noggin may differentially affect the capacity of the BMP ligands to bind BMP receptors and influence keratinocyte proliferation/differentiation and cell fate decision.

Taken together, these data support a concept that signaling pathways involved in the control of skin morphogenesis are highly relevant to the development of skin cancers. ${ }^{3,5,38}$ Our data provide compelling evidence that the BMP antagonist noggin can play an important role in skin tumorigenesis and may significantly compromise tumor suppressor function of BMPs in postnatal skin, at least in part via stimulating the Wnt and Shh signaling pathways. Thus, levels and/or activity of BMP antagonists may determine the predisposition of skin epithelium to carcinogenesis, while pharmacological modulation of BMP activity may provide a new set of tools for skin cancer prevention and management.

\section{Acknowledgments}

We thank Prof. Keiko Funa (University of Gothenburg, Sweden), Dr. Chen Li (University Southern California), Dr. David Jablons (University of California San Francisco), and Dr. Wei Niu (Infinity Pharmaceutical, Inc., Cambridge, Massachusetts) for providing reagents for this study. We also thank Dr. Alexei Sharov (National Institute of Aging, Baltimore, Maryland) for help with analyzing the microarray data.

\section{References}

1. Glick AB, Yuspa SH: Tissue homeostasis and the control of the neoplastic phenotype in epithelial cancers. Semin Cancer Biol 2005 15:75-83

2. Li AG, Lu SL, Han G, Hoot KE, Wang XJ: Role of TGFbeta in skin inflammation and carcinogenesis. Mol Carcinog 2006, 45:389-396

3. Owens DM, Watt FM: Contribution of stem cells and differentiated cells to epidermal tumours. Nat Rev Cancer 2003, 3:444-451

4. Athar M, Tang X, Lee JL, Kopelovich L, Kim AL: Hedgehog signalling in skin development and cancer. Exp Dermatol 2006, 15:667-677

5. Bornstein S, Hoot K, Han GW, Lu SL, Wang XJ: Distinct roles of individual Smads in skin carcinogenesis. Mol Carcinog 2007, 46:660-664

6. Botchkarev VA: Bone morphogenetic proteins and their antagonists in skin and hair follicle biology. J Invest Dermatol 2003, 120:36-47

7. Owens P, Han G, Li AG, Wang XJ: The role of Smads in skin development. J Invest Dermatol 2008, 128:783-790

8. Miyazono K, Maeda S, Imamura T: BMP receptor signaling: transcriptional targets, regulation of signals, and signaling cross-talk. Cytokine Growth Factor Rev 2005, 16:251-263

9. Botchkarev VA, Botchkareva NV, Roth W, Nakamura M, Chen L-H, Herzog W, Lindner G, McMahon JA, Peters C, Lauster R, McMahon AP, Paus R: Noggin is a mesenchymally derived stimulator of hair follicle induction. Nature Cell Biol 1999, 1:158-164

10. Andl T, Ahn K, Kairo A, Chu EY, Wine-Lee L, Reddy ST, Croft NJ, Cebra-Thomas JA, Metzger D, Chambon P, Lyons KM, Mishina $Y$, Seykora JT, Crenshaw EBr, Millar SE: Epithelial Bmpr1a regulates differentiation and proliferation in postnatal hair follicles and is essential for tooth development. Development 2004, 131:2257-2268

11. Kobielak K, Pasolli HA, Alonso L, Polak L, Fuchs E: Defining BMP functions in the hair follicle by conditional ablation of BMP receptor IA. J Cell Biol 2003, 163:609-623

12. Ming Kwan K, Li AG, Wang XJ, Wurst W, Behringer RR: Essential roles of BMPR-IA signaling in differentiation and growth of hair follicles and in skin tumorigenesis. Genesis 2004, 39:10-25

13. Yuhki M, Yamada M, Kawano M, Iwasato $T$, Itohara S, Yoshida $H$, Ogawa M, Mishina Y: BMPR1A signaling is necessary for hair follicle cycling and hair shaft differentiation in mice. Development 2004, 131:1825-1833

14. Botchkarev VA, Botchkareva NV, Nakamura M, Huber O, Funa K, Lauster R, Paus R, Gilchrest BA: Noggin is required for induction of hair follicle growth phase in postnatal skin. FASEB J 2001, 15:2205-2214

15. Sharov AA, Fessing M, Atoyan R, Sharova TY, Haskell-Luevano C, Weiner L, Funa K, Brissette JL, Gilchrest BA, Botchkarev VA: Bone morphogenetic protein (BMP) signaling controls hair pigmentation by means of cross-talk with the melanocortin receptor-1 pathway. Proc Natl Acad Sci USA 2005, 102:93-98

16. Sharov AA, Sharova TY, Mardaryev AN, Tommasi di Vignano A, Atoyan R, Weiner L, Yang S, Brissette JL, Dotto GP, Botchkarev VA: $\mathrm{BMP}$ signaling regulates size of the hair follicles and modulates the expression of cell cycle-associated genes. Proc Natl Acad Sci USA 2006, 103:18166-18171

17. Blessing M, Nanney LB, King LE, Hogan BL: Chemical skin carcinogenesis is prevented in mice by the induced expression of a TGFbeta related transgene. Teratog Carcinog Mutag 1995, 15:11-21

18. Blessing M, Schirmacher P, Kaiser S: Overexpression of bone morphogenetic protein- 6 in the epidermis of transgenic mice: inhibition or stimulation of proliferation depending on the pattern of transgene 
expression and formation of psoriatic lesions. J Cell Biol 1996, 135:227-239

19. He W, Cao T, Smith DA, Myers TE, Wang XJ: Smads mediate signaling of the TGFbeta superfamily in normal keratinocytes but are lost during skin chemical carcinogenesis. Oncogene 2001, 20:471-483

20. Qiao W, Li AG, Owens P, Xu X, Wang XJ, Deng CX: Hair follicle defects and squamous cell carcinoma formation in Smad4 conditional knockout mouse skin. Oncogene 2006, 25:207-217

21. Yang L, Mao C, Teng Y, Li W, Zhang J, Cheng X, Li X, Han X, Xia Z, Deng $H$, Yang $X$ : Targeted disruption of Smad4 in mouse epidermis results in failure of hair follicle cycling and formation of skin tumors. Cancer Res 2005, 65:8671-8678

22. Sneddon JB, Zhen HH, Montgomery K, van de Rijn M, Tward AD, West R, Gladstone H, Chang HY, Morganroth GS, Oro AE, Brown PO: Bone morphogenetic protein antagonist gremlin 1 is widely expressed by cancer-associated stromal cells and can promote tumor cell proliferation. Proc Natl Acad Sci USA 2006, 103:14842-14847

23. Tucker AS, Headon DJ, Courtney JM, Overbeek P, Sharpe PT: The activation level of the TNF family receptor Edar determines cusp number and tooth number during tooth development. Dev Biol 2004, 268:185-194

24. Sharov AA, Dudekula DB, Ko MSH: A web-based tool for principal component and significance analysis of microarray data. Bioinformatics. 2005, 21:2548-2549

25. Sharov AA, Weiner L, Sharova TY, Siebenhaar F, Atoyan R, McNamara CA, Funa K, Gilchrest BA, Brissette JL, Botchkarev VA: Noggin overexpression inhibits eyelid opening by altering epidermal apoptosis and differentiation. EMBO J 2003, 22:2992-3003

26. Grachtchouk M, Mo R, Yu S, Zhang X, Sasaki H, Hui CC, Dlugosz AA: Basal cell carcinomas in mice overexpressing Gli2 in skin. Nat Genet 2000, 24:216-217

27. Reguart N, He B, Xu Z, You L, Lee AY, Mazieres J, Mikami I, Batra S, Rosell R, McCormick F, Jablons DM: Cloning and characterization of the promoter of human Wnt inhibitory factor-1. Biochem Biophys Res Commun 2004, 323:229-234

28. Kitazawa S, Kitazawa R, Tamada H, Maeda S: Promoter structure of human sonic hedgehog gene. Biochim Biophys Acta 1998, 1443:358-363

29. Ishida W, Hamamoto T, Kusanagi K, Yagi K, Kawabata M, Takehara K, Sampatrh TK, Kato M, Miyazono K: Smad6 is a Smad1/5-induced smad inhibitor. characterization of bone morphogenetic protein-responsive element in the mouse Smad6 promoter. J Biol Chem 2000, 239:1-14

30. Hennings $H$, Glick AB, Lowry DT, Krsmanovic LS, Sly LM, Yuspa $\mathrm{SH}$ : FVB/N mice: an inbred strain sensitive to the chemical induction of squamous cell carcinomas in the skin. Carcinogenesis 1993, 14:2353-2358

31. Plikus M, Wang WP, Liu J, Wang X, Jiang TX, Chuong CM: Morphoregulation of ectodermal organs: integument pathology and phenotypic variations in K14-Noggin engineered mice through modulation of bone morphogenic protein pathway. Am J Pathol 2004, 164:1099-1113

32. Fuchs E: Scratching the surface of skin development. Nature 2007 , 445:834-842

33. Oro AE, Higgins KM, Hu Z, Bonifas JM, Epstein EHJ, Scott MP: Basal cell carcinomas in mice overexpressing sonic hedgehog. Science 1997, 276:817-821

34. Gat U, DasGupta R, Degenstein L, Fuchs E: De Novo hair follicle morphogenesis and hair tumors in mice expressing a truncated betacatenin in skin. Cell 1998, 95:605-614

35. Niemann C, Owens DM, Hulsken J, Birchmeier W, Watt FM: Expression of DeltaNLef1 in mouse epidermis results in differentiation of hair follicles into squamous epidermal cysts and formation of skin tumours. Development 2003, 129:95-109

36. Hutchin ME, Kariapper MS, Grachtchouk M, Wang A, Wei L, Cummings
D, Liu J, Michael LE, Glick A, Dlugosz AA: Sustained Hedgehog signaling is required for basal cell carcinoma proliferation and survival: conditional skin tumorigenesis recapitulates the hair growth cycle. Genes Dev 2005, 19:214-223

37. Takeda H, Lyle S, Lazar AJ, Zouboulis CC, Smyth I, Watt FM: Human sebaceous tumors harbor inactivating mutations in LEF1, Nat Med 2006, 12:395-397

38. Yang SH, Andl T, Grachtchouk V, Wang A, Liu J, Ferris L, Wang TS, Glick AB, Millar SE, Dlugosz AA: Pathological responses to oncogenic Hedgehog signaling in skin are dependent on canonical Wnt/ beta-catenin signaling. Nat Genet 2008, 40:1130-1135

39. Morris RJ, Liu Y, Marles L, Yang Z, Trempus C, Li S, Lin JS, Sawicki JA, Cotsarelis G: Capturing and profiling adult hair follicle stem cells. Nature Biotechnol 2004, 22:411-417

40. Rhee H, Polak L, Fuchs E: Lhx2 maintains stem cell character in hair follicles. Science 2006, 312:1946-1949

41. Katoh M: Networking of Wnt, FGF, Notch BMP, and Hedgehog signaling pathways during carcinogenesis. Stem Cell Rev 2007, 3:30-38

42. Li H, Pamukcu R, Thompson WJ: beta-Catenin signaling: therapeutic strategies in oncology. Cancer Biol Ther 2002, 1:621-625

43. Zhang J, He XC, Tong WG, Johnson T, Wiedemann LM, Mishina $Y$, Feng JQ, Li L: Bone morphogenetic protein signaling inhibits hair follicle anagen induction by restricting epithelial stem/progenitor cell activation and expansion. Stem Cells 2006, 24:2826-2839

44. Haramis AP, Begthel $H$, van den Born M, van Es J, Jonkheer S, Offerhaus GJ, Clevers $\mathrm{H}$ : De novo crypt formation and juvenile polyposis on BMP inhibition in mouse intestine. Science 2004, 303:1684-1686

45. Lo Celso C, Prowse DM, Watt FM: Transient activation of beta-catenin signalling in adult mouse epidermis is sufficient to induce new hair follicles but continuous activation is required to maintain hair follicle tumours. Development 2004, 131:1787-1799

46. Kobielak K, Stokes N, de la Cruz J, Polak L, Fuchs E: Loss of a quiescent niche but not follicle stem cells in the absence of bone morphogenetic protein signaling. Proc Natl Acad Sci USA 2007, 104:10063-10068

47. Palmer HG, Anjos-Afonso F, Carmeliet G, Takeda H, Watt FM: The vitamin $\mathrm{D}$ receptor is a Wnt effector that controls hair follicle differentiation and specifies tumor type in adult epidermis. PLOS ONE 2008, 3:e1483

48. Rubin JS, Barshishat-Kupper M, Feroze-Merzoug F, Xi ZF: Secreted WNT antagonists as tumor suppressors: pro and con. Front Biosci 2006, 11:2093-2105

49. Rendl M, Polak L, Fuchs E: BMP signaling in dermal papilla cells is required for their hair follicle-inductive properties. Genes Dev 2008, 22:543-557

50. Chiba T, Zheng YW, Kita K, Yokosuka O, Saisho H, Onodera M, Miyoshi H, Nakano M, Zen Y, Nakanuma Y, Nakauchi H, Iwama A, Taniguchi H: Enhanced self-renewal capability in hepatic stem/progenitor cells drives cancer initiation. Gastroenterology 2007, 133:937-950

51. Malanchi I, Peinado H, Kassen D, Hussenet T, Metzger D, Chambon P, Huber M, Hohl D, Cano A, Birchmeier W, Huelsken J: Cutaneous cancer stem cell maintenance is dependent on beta-catenin signalling. Nature 2008, 452:650-653

52. Blanpain C, Lowry WE, Geoghegan A, Polak L, Fuchs E: Self-renewal, multipotency, and the existence of two cell populations within an epithelial stem cell niche. Cell 2004, 118:635-648

53. Mou C, Jackson B, Schneider P, Overbeek PA, Headon DJ: Generation of the primary hair follicle pattern. Proc Natl Acad Sci USA 2006, 103:9075-80

54. Pummila M, Fliniaux I, Jaatinen R, James MJ, Laurikkala J, Schneider P, Thesleff I, Mikkola ML: Ectodysplasin has a dual role in ectodermal organogenesis: inhibition of Bmp activity and induction of Shh expression. Development 2007, 134:117-25 